\title{
Author Correction: The potential of future foods for sustainable and healthy diets
}

A. Parodi, A. Leip, I. J. M. De Boer, P. M. Slegers, F. Ziegler, E. H. M. Temme (D), M. Herrero D, H. Tuomisto, H. Valin (D), C. E. Van Middelaar, J. J. A. Van Loon and H. H. E. Van Zanten (i)

Correction to: Nature Sustainability https://doi.org/10.1038/s41893-018-0189-7, published online 14 December 2018.

In the version of this Article originally published, in Supplementary Table 7, the energy and land-use values for mealworms in Thevenot et al. were mistakenly swapped. The correct values are $65.39 \mathrm{MJ}$ for energy use and $4.31 \mathrm{~m}^{2}$ for land use. In the same table, the energy and land use values for black soldier fly in Salome et al. were incorrectly given as $0.14 \mathrm{MJ}$ and $41.67 \mathrm{~m}^{2}$; they should have read 7.248 MJ and $0.024 \mathrm{~m}^{2}$ (respectively). Correcting these values has led to corresponding changes in Fig. 3, Supplementary Figs 2 and 4 and Supplementary Table 8 .

Additionally, in the panel of Fig. 3 that contains information about vitamin A, the land-use values of 593 for pork and 1914 for beef were incorrect, and should have been 666 and 3238, respectively.
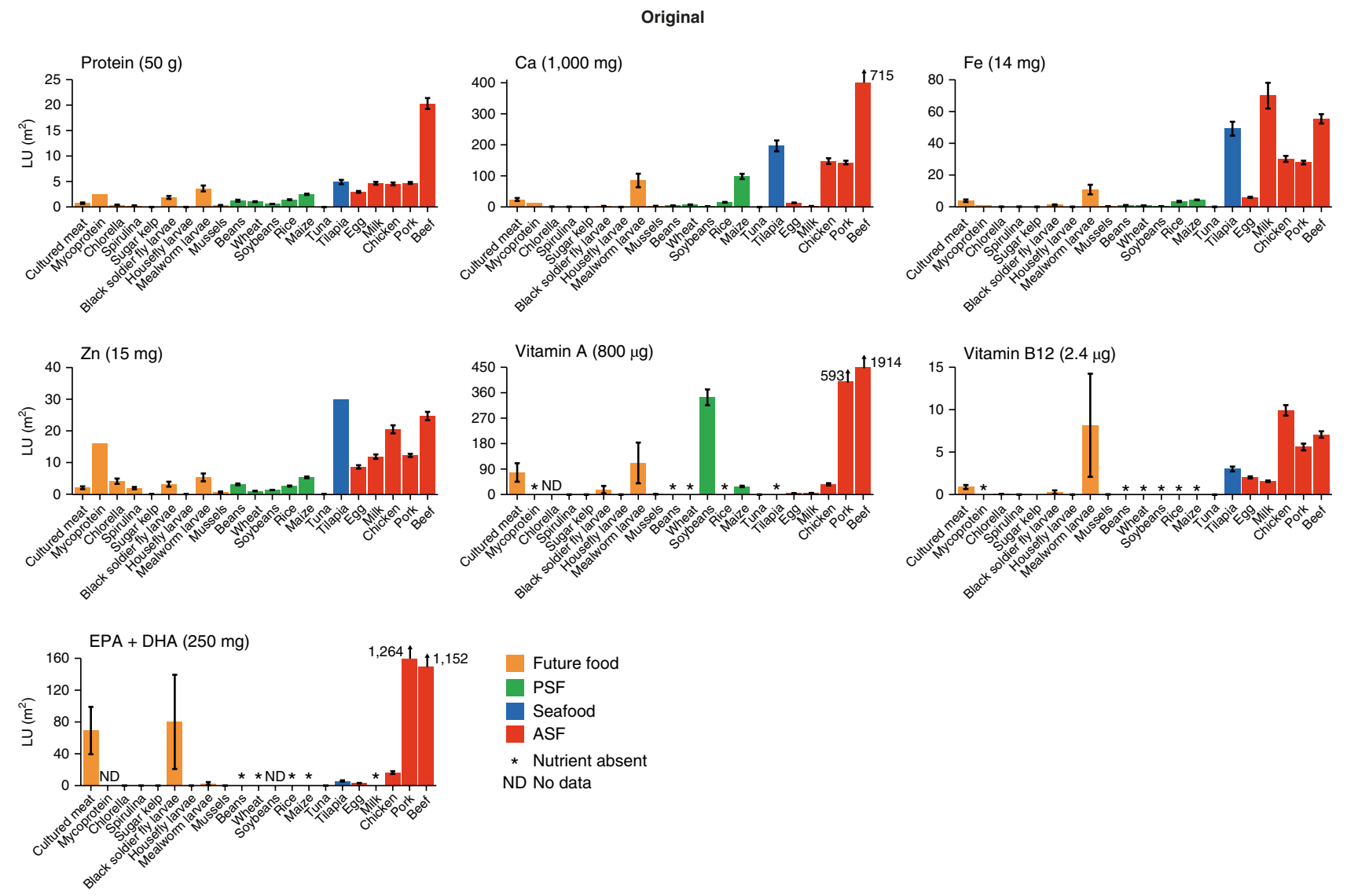


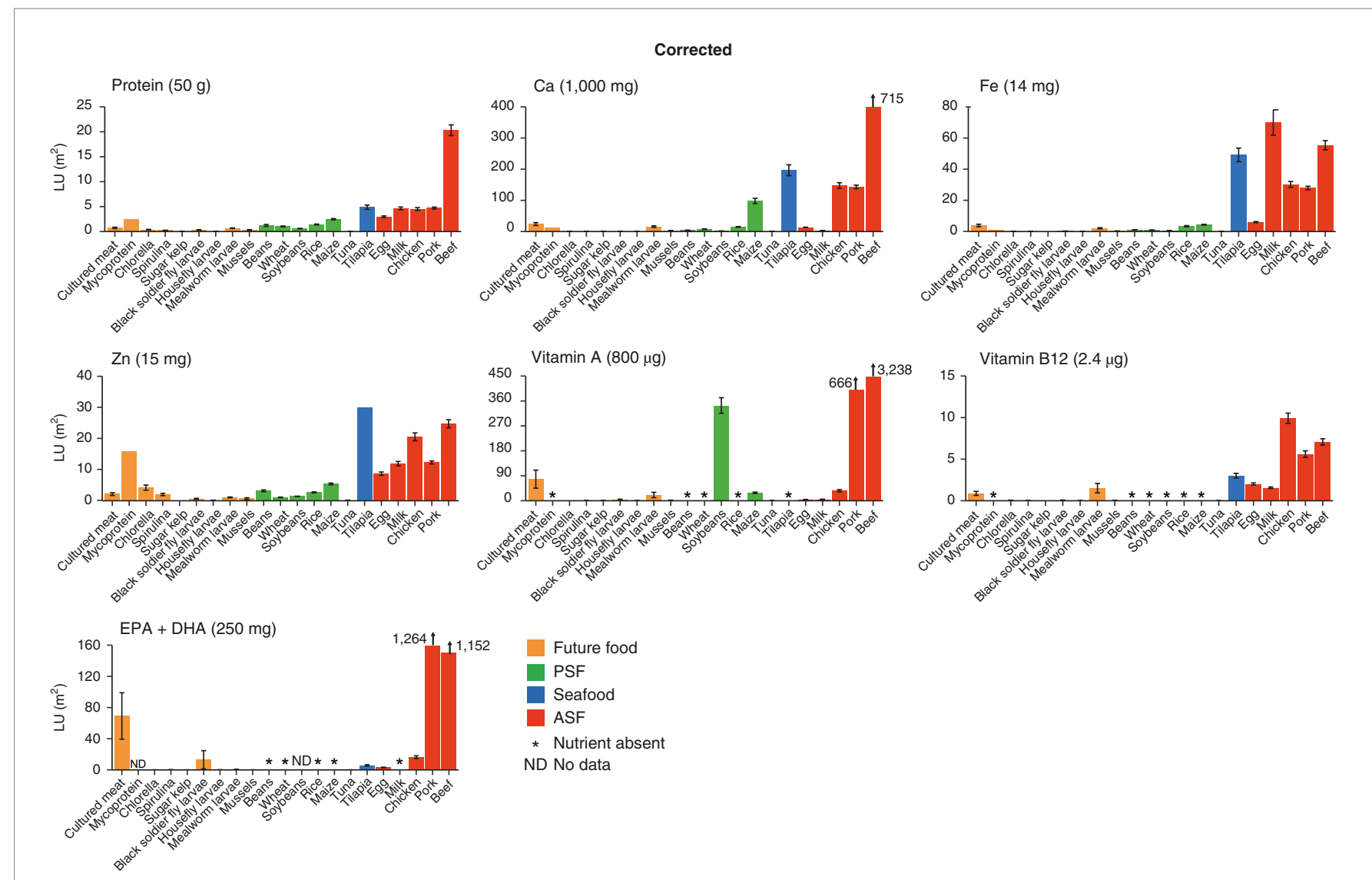

Fig. 3 | Original and Corrected. 
Original
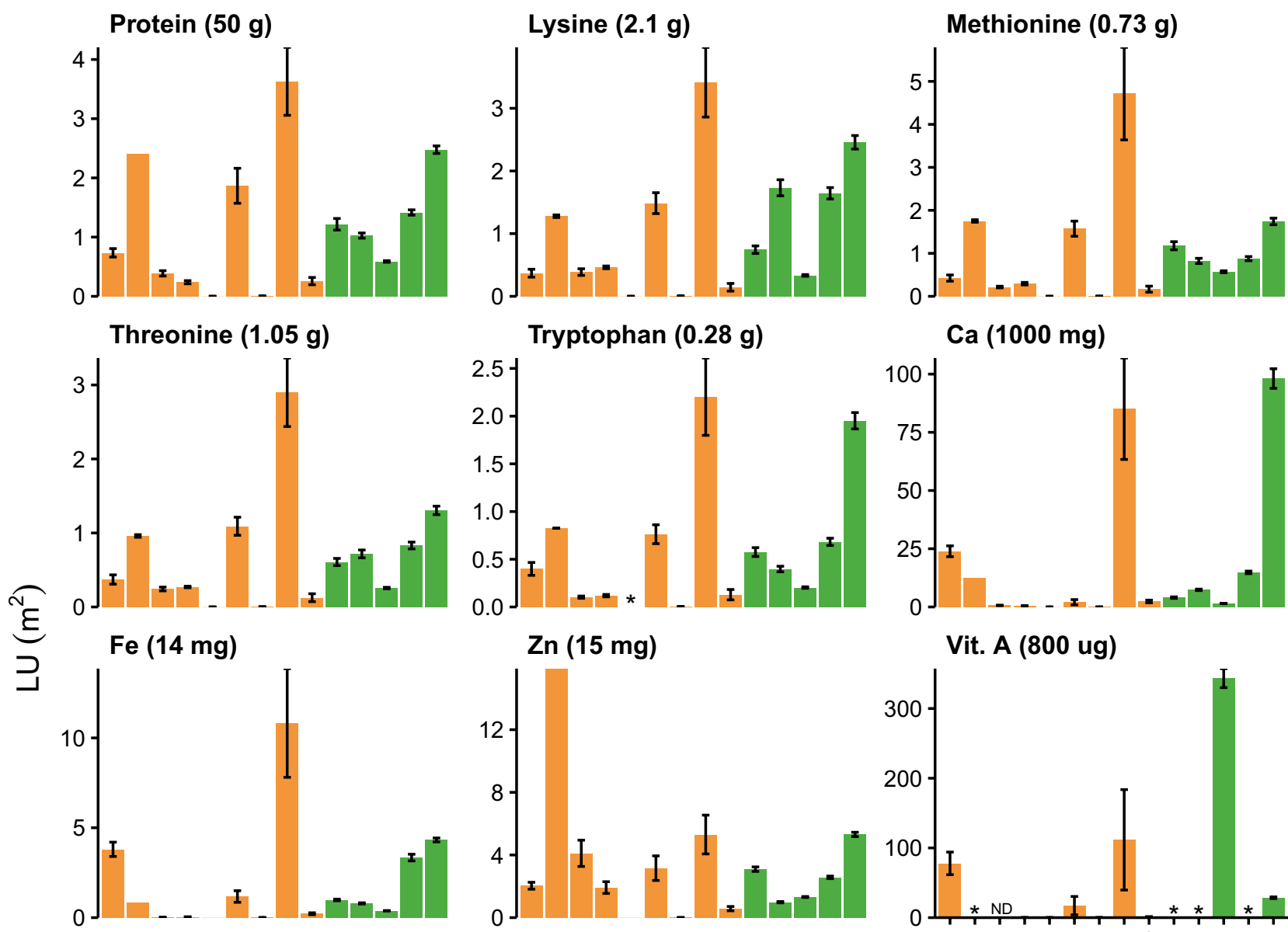

$\mathrm{Ca}(1000 \mathrm{mg})$

Vit. B12 (2.4 ug)
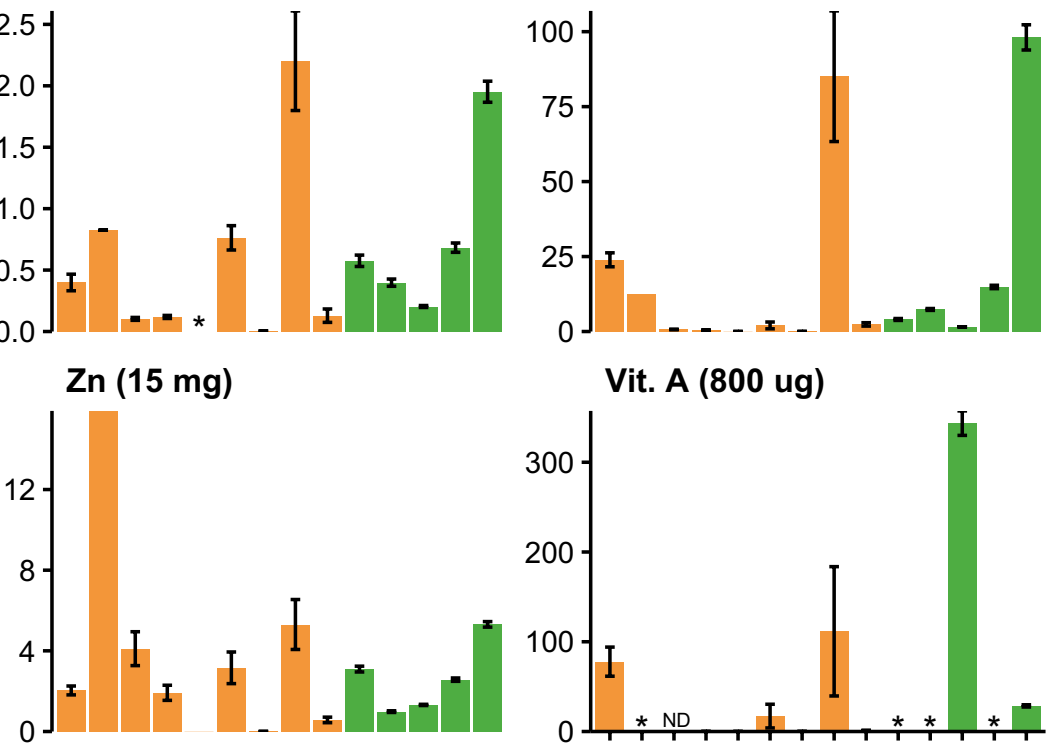

Vit. A (800 ug)
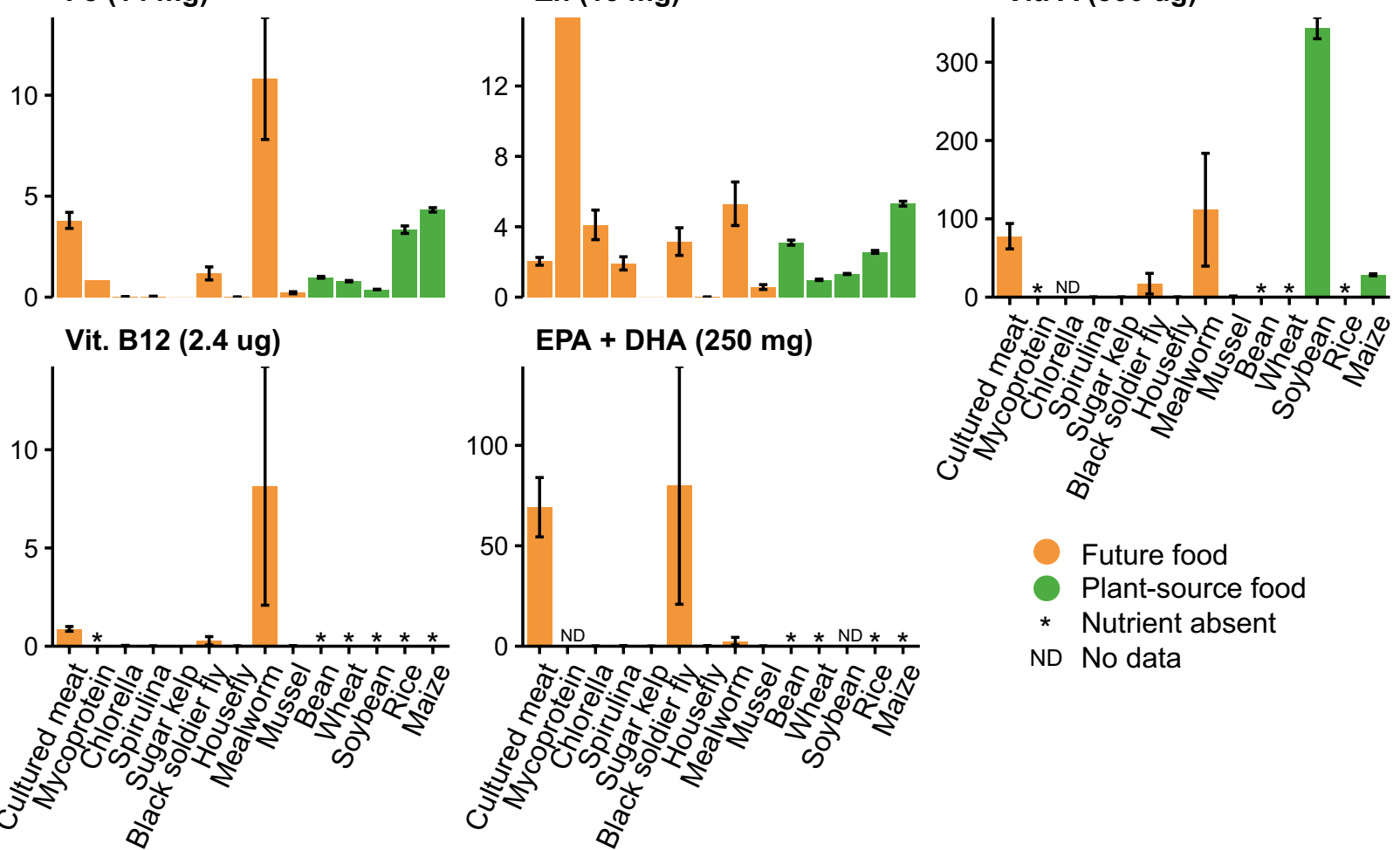

Future food

Plant-source food

* Nutrient absent

ND No data 
Corrected

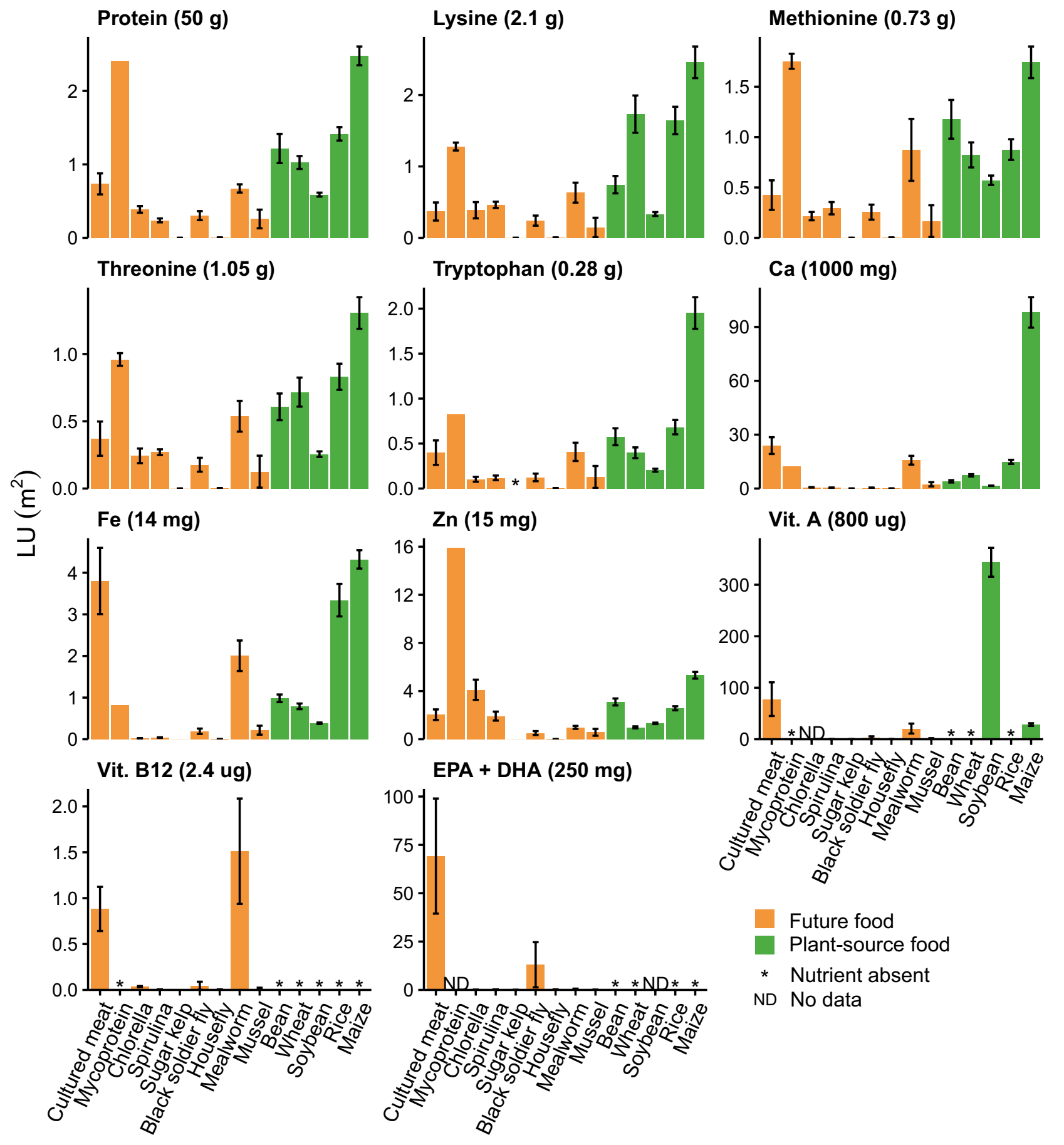

Supplementary Fig. 2 | Original and Corrected. 


\section{Original}
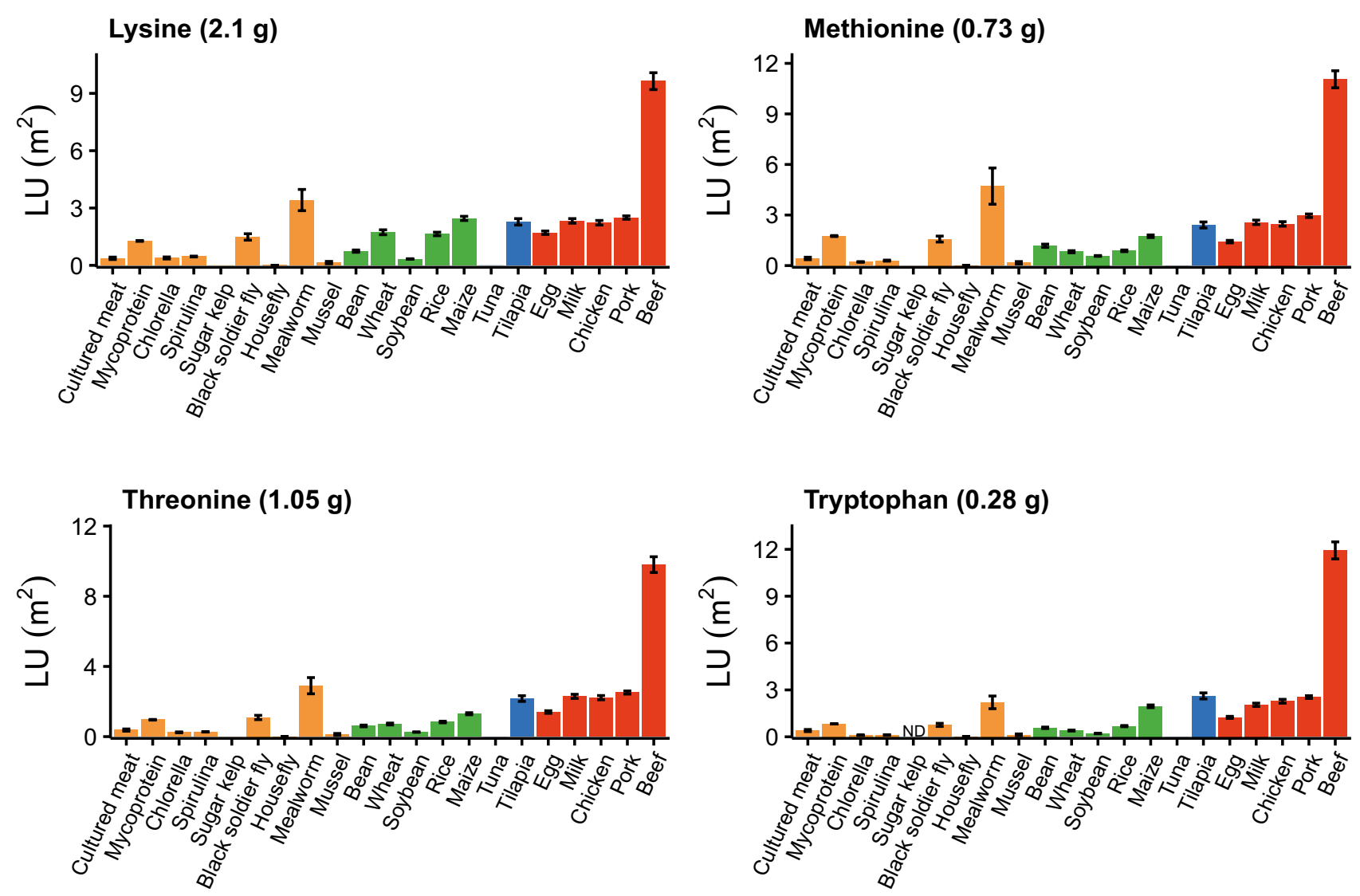

Future food

Plant-source food

Seafood

Animal-source food * Nutrient absent

ND No data 

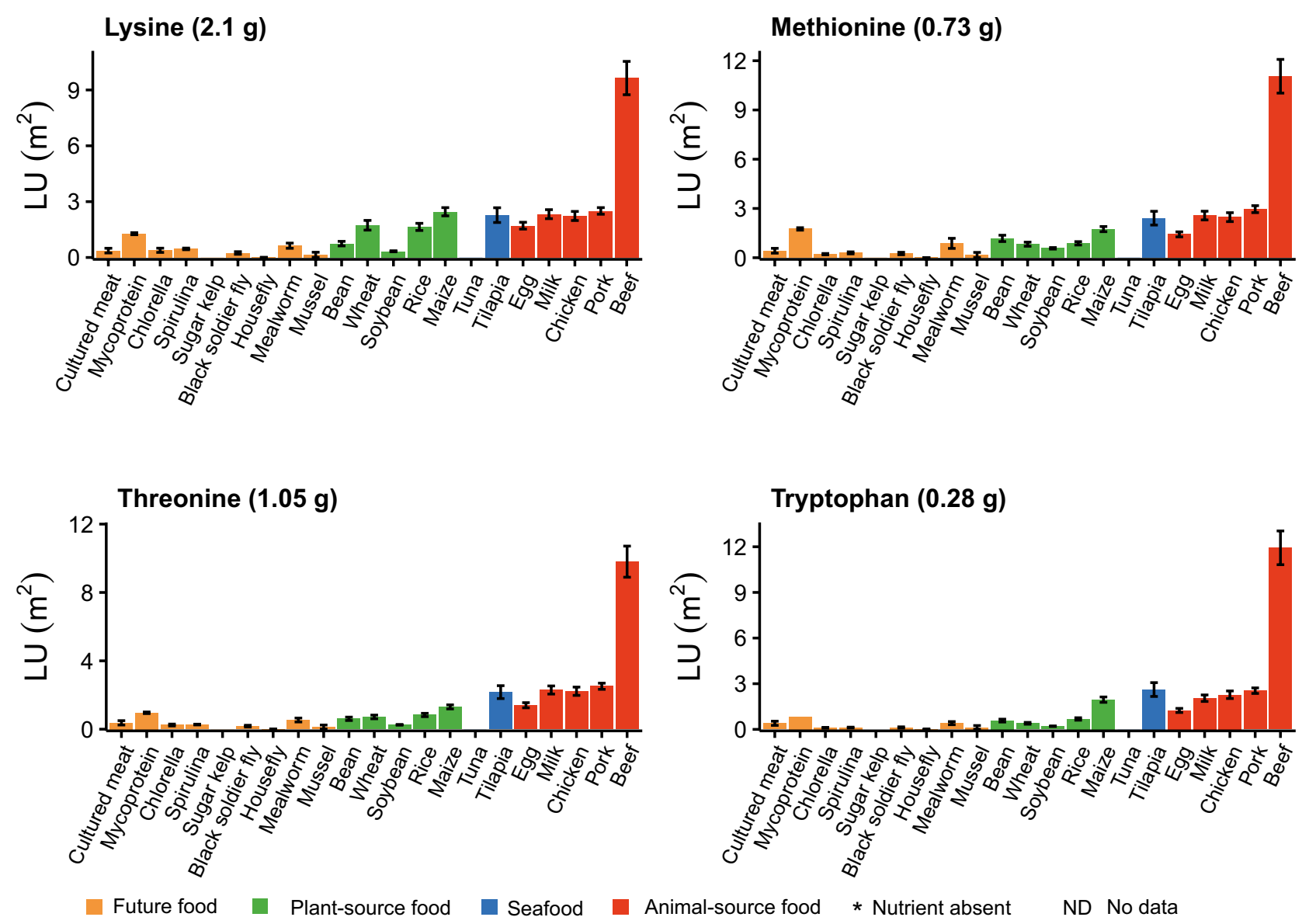

Supplementary Fig. 4 | Original and Corrected.

Published online: 25 March 2019

https://doi.org/10.1038/s41893-019-0268-4 